\title{
泪 University of Glasgow
}

McLennan, A. G., Ganin, A. Y., Takabayashi, Y., Colman, R. H., Zadik, R. H., Rosseinsky, M. J., and Prassides , K. (2014) Synthesis of facecentred cubic Cs3C60 in THF. Faraday Discussions, 173, pp. 95-103.

Copyright (C) 2014 RSC

Version: Accepted

http://eprints.gla.ac.uk/105103/

Deposited on: 01 July 2015

Enlighten - Research publications by members of the University of Glasgow http://eprints.gla.ac.uk 


\title{
Synthesis of face-centred cubic $\mathrm{Cs}_{3} \mathrm{C}_{60}$ in $\mathrm{THF}$
}

\author{
Alec G. McLennan, ${ }^{a}$ Alexey Y. Ganin, ${ }^{a, c}$ Yasuhiro Takabayashi, ${ }^{b}$ \\ Ross H. Colman, ${ }^{\mathrm{b}}$ Ruth H. Zadik, ${ }^{\mathrm{b}}$ Matthew J. Rosseinsky ${ }^{\mathrm{a} *}$ and \\ Kosmas Prassides ${ }^{\mathbf{b}, \mathbf{d}_{*}}$ \\ ${ }_{5}$ DOI: 10.1039/b000000x [DO NOT ALTER/DELETE THIS TEXT]
}

A solution chemistry synthetic route yields $\mathrm{Cs}_{3} \mathrm{C}_{60}$ with the face-centred cubic structure. The described method uses well-established Schlenk techniques and THF as a solvent. The controlled addition of an organometallic salt reducing agent prevents the formation of $\mathrm{C}_{60}{ }^{4-}$ salts. The final ${ }_{10}$ product can be precipitated from the solution using hexane as an antisolvent.

\section{Introduction}

Solution chemistry methods have been an important source of novel alkali-metal fullerides and proved especially advantageous for the synthesis of ternary phases or 15 sodium intercalated compounds where better control over stoichiometry and homogeneity of the product is required. ${ }^{1-6}$ The viability of these methods was heralded by the successful synthesis of the long-sought after highly-expanded $\mathrm{Cs}_{3} \mathrm{C}_{60}$ fulleride which surprisingly, depending on the synthesis conditions, adopts two polymorphic structures which become superconducting under pressure. ${ }^{7-10}$ ${ }_{20}$ While reaction of three equivalents of $\mathrm{Cs}$ with $\mathrm{C}_{60}$ in liquid methylamine produced ca. $78 \%$ of a phase with body-centred cubic arrangement of $\mathrm{C}_{60}{ }^{3-}$ anions (A15structured) replacement of the solvent by liquid ammonia yielded up to $86 \%$ of the face-centred cubic (FCC) polymorph (Figure 1). ${ }^{7,8}$

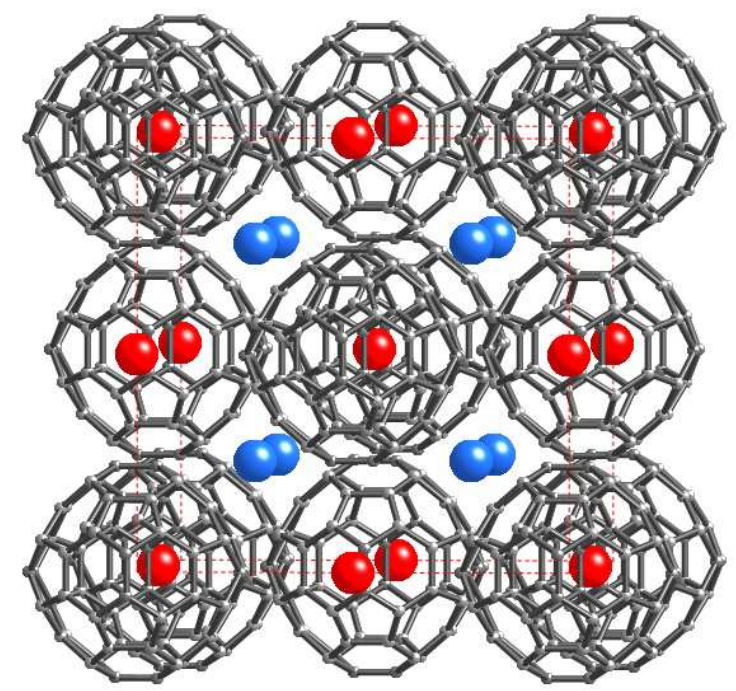

${ }_{25}$ Fig.1 Face-centred cubic structure (space group $F m \overline{3} m$ ) of $\mathrm{Cs}_{3} \mathrm{C}_{60}$ represented using only one $(F m \overline{3})$ of the two disordered $\mathrm{C}_{60}$ orientations. The $\mathrm{Cs}$ cations are situated in both the tetrahedral (blue, mean Cs-C distance $3.45 \AA$ ) and octahedral (red, mean Cs-C distance $3.90 \AA ̊$ A ) interstitial sites.

[journal], [year], [vol], 00-00|1

This journal is @ The Royal Society of Chemistry [year] 
Regardless of the solvent used both as-prepared products contained $\mathrm{Cs}_{1} \mathrm{C}_{60}$ and $\mathrm{Cs}_{4} \mathrm{C}_{60}$ (BCO) phases as impurities. In situ and ex situ PXRD measurements on repeatedly annealed samples confirmed that the amount of $\mathrm{Cs}_{4} \mathrm{C}_{60}$ could be reduced upon annealing. ${ }^{7,} 10$ This was in contrast to the earlier work proposing ${ }_{5}$ disproportionation of $\mathrm{Cs}_{3} \mathrm{C}_{60}$ after annealing at higher temperatures. ${ }^{11}$ Therefore, it is possible that $\mathrm{Cs}_{4} \mathrm{C}_{60}$ originates from the synthesis in liquid amine due to the large reduction potential of metallic caesium. Cyclic voltammetry measurements indicate that reduction potentials in the range of $\mathrm{E}_{1 / 2}{ }^{0 / 1-}=-1.5,-2.15$ and $-3.02 \mathrm{~V}$ vs SCE are required to achieve $\mathrm{C}_{60}{ }^{-3}, \mathrm{C}_{60}{ }^{-4}$ and $\mathrm{C}_{60}{ }^{-6}$ oxidation state respectively and caesium ${ }_{10}\left(\mathrm{E}_{1 / 2}{ }^{+/ 0}=-2.785\right.$ vs. SCE$)$ can reduce $\mathrm{C}_{60}$ to the $\mathrm{C}_{60}{ }^{-6}$ charge state. ${ }^{12-14}$ As a result, precise control of composition within the stable $\mathrm{Cs}_{\mathrm{x}} \mathrm{C}_{60}$ phases may be challenging. Broederick et al. proposed an elegant solution synthesis of $\mathrm{K}_{3} \mathrm{C}_{60}$ by using $\mathrm{K}\left[\mathrm{Mn}\left(\mathrm{Cp}^{*}\right)_{2}\right]$ as a reducing agent. ${ }^{15}$ With a reduction potential of $\mathrm{E}_{1 / 2}{ }^{0 / 1-}=-2.17$ vs SCE $\mathrm{K}\left[\mathrm{Mn}\left(\mathrm{Cp}^{*}\right)_{2}\right]$ was a milder reagent than potassium metal $\left(\mathrm{E}_{1 / 2}^{+/ 0}=-2.7 \mathrm{~V}\right.$ vs ${ }_{15} \mathrm{SCE}$ ) and produced a phase-pure superconducting $\mathrm{K}_{3} \mathrm{C}_{60}$ fulleride. ${ }^{15},{ }^{16}$ It is reasonable to anticipate that a similar approach if applied to the $\mathrm{Cs}_{-} \mathrm{C}_{60}$ system could reduce or completely eliminate the competing $\mathrm{Cs}_{4} \mathrm{C}_{60}$ phase. In this work we have demonstrated that control over stoichiometry by using $\mathrm{Cs}\left[\mathrm{Mn}\left(\mathrm{Cp}^{*}\right)_{2}\right]$ as the reducing agent can produce high quality samples of the $\mathrm{Cs}_{3} \mathrm{C}_{60}$ FCC polymorph.

\section{${ }_{20}$ Results and discussion}

Tetrahydrofuran (THF) was used as an alternative to liquid ammonia $\left(\mathrm{NH}_{3}\right)$ and methylamine (MA) as it offered the opportunity to perform the reaction at ambient conditions without the use of cryogenics and permitted the manipulation of the reaction media by standard Schlenk techniques facilitating administration of the 25 reducing agent in a controlled fashion.

The initial step of preparing $\mathrm{Cs}_{3} \mathrm{C}_{60}$ required synthesis of the $\mathrm{Cs}\left[\mathrm{Mn}(\mathrm{Cp} *)_{2}\right]$ reducing agent. To the best of our knowledge, there have been no previous literature reports on the synthesis of $\mathrm{Cs}\left[\mathrm{Mn}\left(\mathrm{Cp}^{*}\right)_{2}\right]$. Therefore, a synthetic protocol for $\mathrm{Cs}\left[\mathrm{Mn}\left(\mathrm{Cp}^{*}\right)_{2}\right]$ was developed based on a modification of the method outlined for the 30 synthesis of $\mathrm{Na}\left[\mathrm{Mn}(\mathrm{Cp} *)_{2}\right]$ (Scheme I and Experimental section). ${ }^{16}$

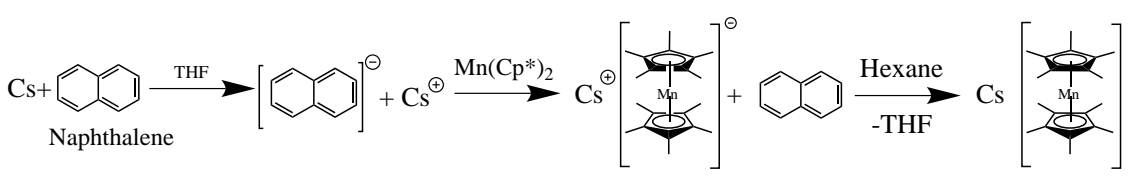

Scheme I Reaction scheme for the synthesis of the $\mathrm{Cs}\left[\mathrm{Mn}\left(\mathrm{Cp}^{*}\right)\right]_{2}$ reducing agent.

Compared to the sodium naphthalide its caesium analogue is less soluble in THF (solubility evaluated in this work $0.35 \mathrm{~mol} / \mathrm{L}$ ) but a fourfold increase in solvent 35 volume ensured the initial reaction between $\mathrm{Cs}$ and naphthalene produced a fully dissolved product. Adding the solution to the $\mathrm{Mn}\left(\mathrm{Cp}^{*}\right)_{2}$ gave $92.8 \%$ yields of the $\mathrm{Cs}\left[\mathrm{Mn}\left(\mathrm{Cp}^{*}\right)_{2}\right]$ similar to those quoted before for the $\mathrm{Na}\left[\mathrm{Mn}\left(\mathrm{Cp}^{*}\right)_{2}\right] .{ }^{16}$ The composition of the final bright orange highly air-sensitive product corresponded to $\mathrm{Cs}_{1.0(1)}\left[\mathrm{Mn}\left(\mathrm{Cp}^{*}\right)_{2}\right]$, according to the microanalysis results. Powder X-ray diffraction 40 studies showed that the product was free from $\mathrm{Mn}\left(\mathrm{Cp}^{*}\right)_{2}$ impurities (Fig. S1).

The optimised synthesis of the $\mathrm{Cs}_{3} \mathrm{C}_{60}$ material required slow addition over 90 minutes of the $\mathrm{Cs}\left[\mathrm{Mn}\left(\mathrm{Cp}^{*}{ }_{2}\right)\right]$ reducing agent to a $\mathrm{C}_{60}$ suspension in THF (Scheme II and Experimental section).

2 | [journal], [year], [vol], 00-00

This journal is @ The Royal Society of Chemistry [year] 


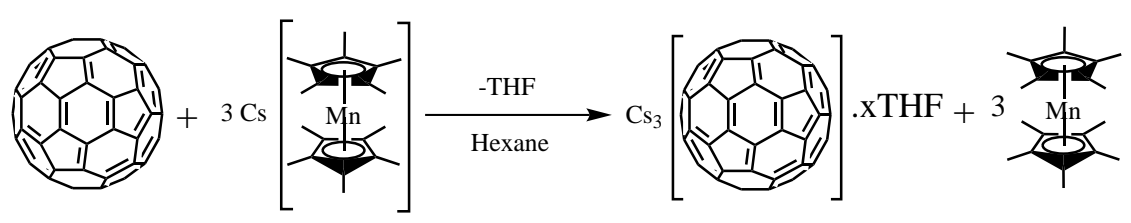

Scheme II Schematic representation of the reaction between $\operatorname{Cs}\left[\mathrm{Mn}\left(\mathrm{Cp}^{*}\right)\right]_{2}$ and $\mathrm{C}_{60}$ to afford solvated $\mathrm{Cs}_{3} \mathrm{C}_{60}$.

The slow addition of the reducing agent in a controlled manner was key to the 5 success of the synthetic procedure. This was done to avoid the risk that rapid addition of the reducing agent would reduce $\mathrm{C}_{60}$ beyond an oxidation state of -3 to $\mathrm{Cs}_{4} \mathrm{C}_{60}$. The antisolvent precipitation of the $\mathrm{Cs}_{3} \mathrm{C}_{60} \times \mathrm{xHF}$ solvated product by hexane was the final and rather sensitive step in which the yield and crystallinity of the product could be affected. In this step, hexane played two roles; firstly it 10 precipitated the solvated product and secondly it dissolved the $\operatorname{Mn}\left(\mathrm{Cp}^{*}\right)_{2}$ starting material. The as-made material was very sensitive to solvent loss, quickly losing its red colouring and crystallinity while becoming black. Annealing of the as-made material at $350^{\circ} \mathrm{C}$ was required in order to obtain high quality solvent-free crystalline material (Sample 1) suitable for synchrotron X-ray powder diffraction 15 studies.

Synthesis at twice this scale was also undertaken (Experimental section). The reaction itself proceeds in exactly the same fashion as its predecessor, first leading to a red solution and then on precipitation to a red-brown powder, which quickly turns black upon loss of the solvent. The final annealing step at $350^{\circ} \mathrm{C}$ was required 20 for the isolation of a high quality material (Sample 2).

The annealed products were characterised by synchrotron X-ray powder diffraction with the diffraction profiles shown in Fig. 2. The synchrotron data were refined by Rietveld methods against the $F m \overline{3} m$ structure model. The comparison of the refined parameters with those reported before ${ }^{7}$ for samples synthesized via 25 ammonia and amine chemistry is summarized in Table 1 . Both products showed reduction in the unit cell volumes by 0.11 and $0.28 \%$ for 1 and 2 respectively when compared with those reported in the literature. Although the diffraction patterns appear to be free from any $\mathrm{Cs}_{4} \mathrm{C}_{60}$ phase peaks, they contain reflections which can be associated with the presence of a different impurity phase. This phase was accounted 30 for in the course of the refinements by the pattern decomposition Pawley method using a monoclinic unit cell (space group $C 2 / m$ ) based on the structure model proposed for the solvated potassium analogue, $\mathrm{K}_{3} \mathrm{C}_{60} \cdot 14 \mathrm{THF} .{ }^{17}$

The refined composition of the majority FCC phase is close to that of the ideal $\mathrm{Cs}_{3} \mathrm{C}_{60}$ structure as it is also evident from Raman spectroscopy (Table 2 and Fig. S2) 35 which showed a single peak in the $1400 \mathrm{~cm}^{-1}<\bar{v}<1600 \mathrm{~cm}^{-1}$ region, assigned to the $A_{g}(2)$ mode of $\mathrm{C}_{60}$ consistent with -3 oxidation state. The $A_{g}(2)$ pentagonal pinch mode has been found particularly sensitive to fulleride charge state, showing empirically an $\sim 6 \mathrm{~cm}^{-1}$ shift with each additional integer $\mathrm{C}_{60}$ charge. ${ }^{18}$ Unlike the literature reference material, which was prepared by amine chemistry and showed 40 splitting of the $A_{g}(2)$ peak due to the presence of the impurity $\mathrm{CsC}_{60}$ and $\mathrm{Cs}_{4} \mathrm{C}_{60}$ phases, the products of THF chemistry display only single peaks in their Raman spectra. However, a significant amount of peak broadening present could indicate some disorder within the system.

[journal], [year], [vol], 00-00|3 

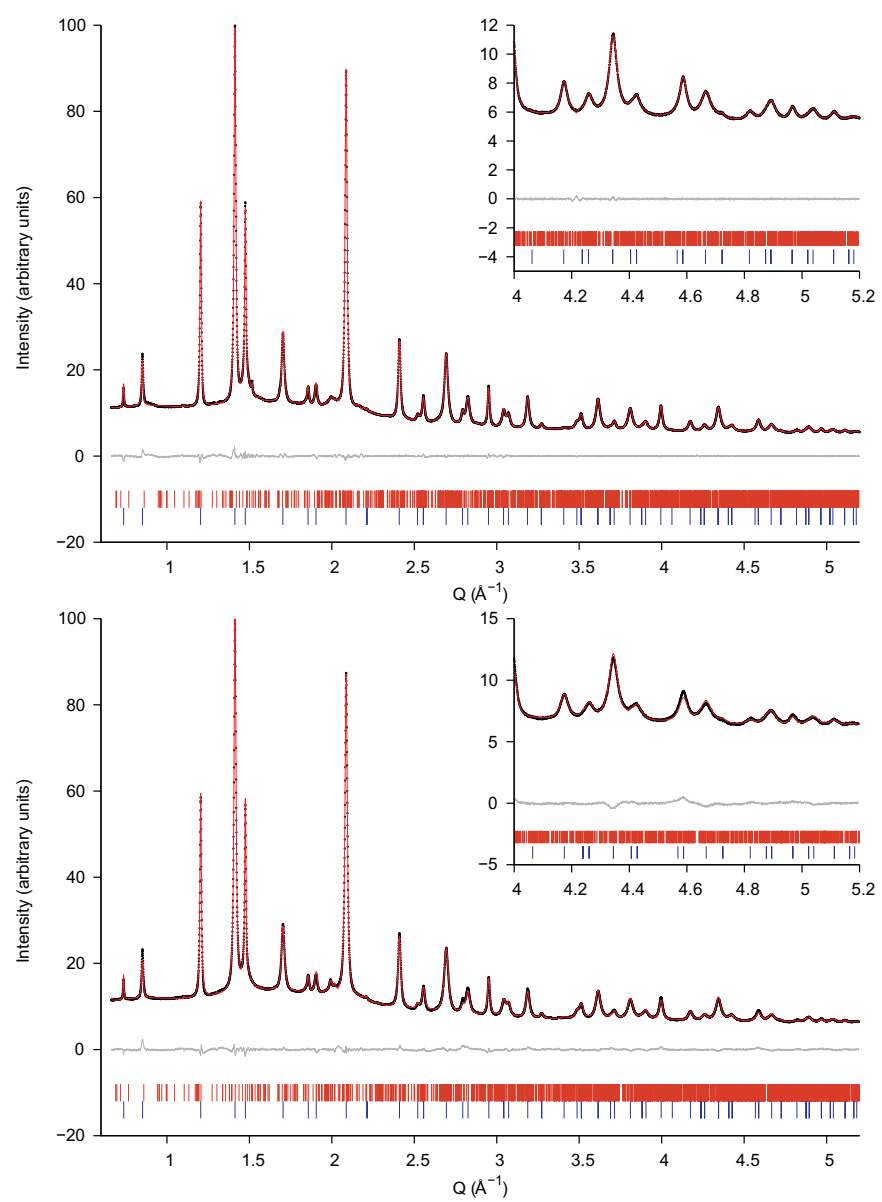

Fig.2 Observed (black dots) and calculated (red line) synchrotron X-ray $(\lambda=0.82716 \AA$ ) powder diffraction patterns of the $\mathrm{Cs}_{3} \mathrm{C}_{60}$ sample $\mathbf{1}$ (top) and $\mathbf{2}$ (bottom) at room temperature. The grey solid line shows the difference profile and the tick marks the reflection positions of the FCC (blue) and 5 solvated (orange) $\mathrm{Cs}_{3} \mathrm{C}_{60}$ phases. Refined parameters and agreement indices are given in Table 1.

Table 1 Composition, phase fractions, unit cell parameters and volume per $\mathrm{C}_{60}$ for the fcc (space group $F m \overline{3} m$ ) $\mathrm{Cs}_{3} \mathrm{C}_{60}$. The unit cell parameters of the monoclinic (space group $C 2 / m$ ) solvated impurity phase were: Sample 1: $a=19.306(2), b=18.450(2), c=14.163(2) \AA ; \beta=110.53(1)^{\circ}$.

Sample 2: $\left.a=19.293(2), b=17.484(2), c=14.244(2) \AA ; \beta=110.69(1)^{\circ}\right)$. The refined atomic 10 parameters are summarized in Table S1 and S2.

\begin{tabular}{|c|c|c|c|}
\hline Parameter & Sample 1 & Sample 2 & Ref [7] \\
\hline Scale (mg) & 100 & 200 & 278 \\
\hline$\lambda(\AA)$ & 0.82716 & 0.82716 & 0.40004 \\
\hline BCO (wt.\%) & 0 & 0 & $6.7(2)$ \\
\hline FCC (wt.\%) & 100 & 100 & $85.88(2)$ \\
\hline A15 (wt.\%) & 0 & 0 & $3.31(5)$ \\
\hline $\mathrm{CsC}_{60}($ wt.\%) & 0 & 0 & $4.10(6)$ \\
\hline $\begin{array}{c}a, \stackrel{\AA}{A} \\
\text { FCC } \operatorname{vper} C_{60}\left(\AA^{3}\right)\end{array}$ & $\begin{array}{l}14.7560(2) \\
803.24(3)\end{array}$ & $\begin{array}{l}14.7479(2) \\
801.92(3)\end{array}$ & $\begin{array}{c}14.76151(8) \\
804.14(1)\end{array}$ \\
\hline $\begin{array}{c}\text { FCC xrd } \\
\text { composition }\end{array}$ & $\mathrm{Cs}_{2.942(2)} \mathrm{C}_{60}$ & $\mathrm{Cs}_{2.947(1)} \mathrm{C}_{60}$ & $\mathrm{Cs}_{2.901(6)} \mathrm{C}_{60}$ \\
\hline
\end{tabular}

4 | [journal], [year], [vol], 00-00 
Table 2 Summary of the results of Lorentzian fits to the Raman data. $\omega_{0}$ represents the peak position, $\Gamma$ the peak width and $\mathrm{A}$ the peak area.

\begin{tabular}{|c|c|c|c|c|}
\hline Parameter & \multicolumn{2}{|c|}{ Ganin et.al. ${ }^{7}$} & Sample 1 & Sample 2 \\
\hline Peak & 1 & 2 & 1 & 1 \\
\hline$\omega_{0}\left(\mathrm{~cm}^{-1}\right)$ & $1446.70(2)$ & $1456.34(4)$ & $1448.15(3)$ & $1446.25(2)$ \\
\hline$\Gamma\left(\mathbf{c m}^{-1}\right)$ & $6.89(8)$ & $13.9(8)$ & $14.8(1)$ & $12.37(8)$ \\
\hline A $\left(\mathrm{cm}^{-1} \cdot\right.$ counts $)$ & $10.3(1)$ & $3.4(2)$ & $23.6(2)$ & $18.5(1)$ \\
\hline
\end{tabular}

Temperature-dependent magnetisation measurements under pressure revealed that both

${ }_{5}$ Sample 1 and 2 become superconducting upon pressurisation (Fig. S3). The transition into superconducting state is initially observed at $T_{c}=29 \mathrm{~K}$ under a pressure of $0.26 \mathrm{GPa}$ which are comparable to the values observed for the products prepared by amine/ammonia chemistry routes (Fig. 3). $T_{c}$ increases to the maximum of 33.5 and 33.0K for Sample $\mathbf{1}$ and $\mathbf{2}$ respectively. Although the materials show typical 10 superconducting "dome"-type behaviour due to the tuning of the interfulleride separation by the pressure, both samples display lower superconducting temperatures compared with the literature analogues. The disorder (Raman linewidth) and reduced unit cell dimensions could be possible explanations for the inferior superconducting properties of the materials prepared using $\mathrm{Cs}\left[\mathrm{Mn}\left(\mathrm{Cp}^{*}\right)_{2}\right]$ as a reducing agent in THF. Further 15 optimisation of the proposed synthetic procedure is required to produce $\mathrm{Cs}_{3} \mathrm{C}_{60}$ materials with improved superconducting properties, but the present work demonstrates that control of the redox behaviour of the reducing agents reduces contamination by other $\mathrm{C}_{60}$ charge states.

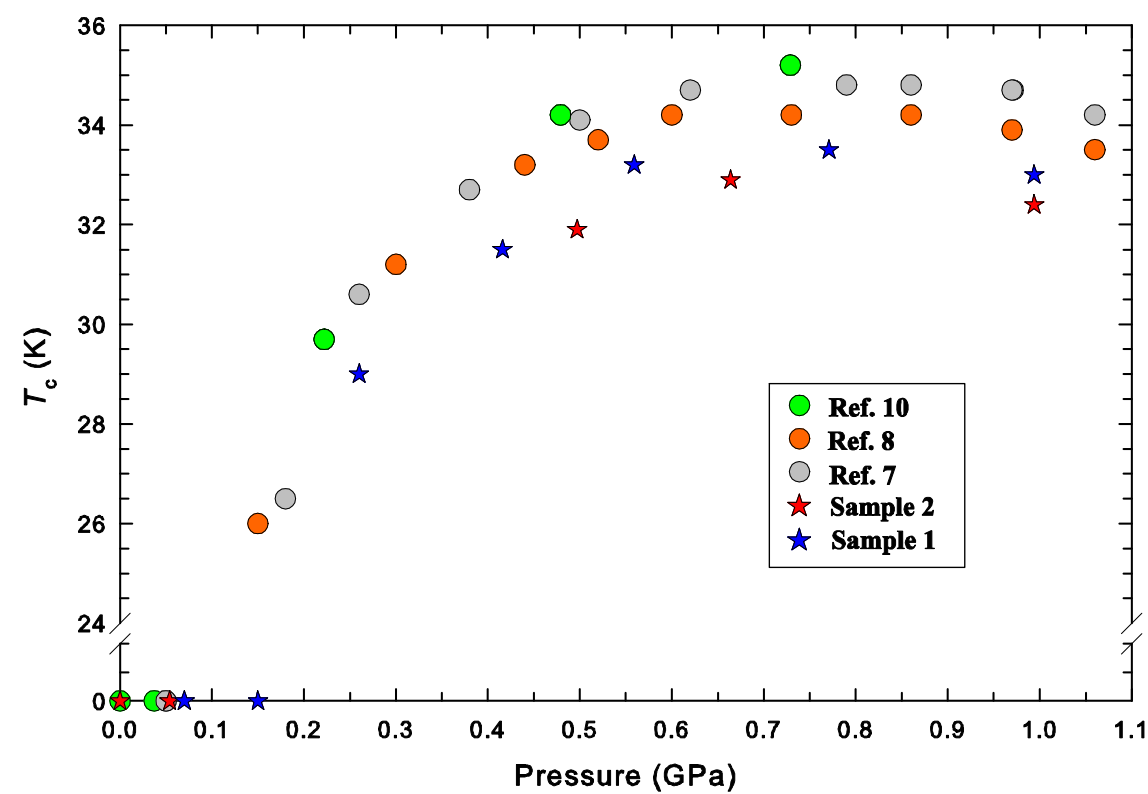

$20 \quad$ Fig.3 Superconducting transition temperatures plotted as a function of the applied pressure for $\mathrm{Cs}_{3} \mathrm{C}_{60}$ samples 1 (blue stars) and $\mathbf{2}$ (red stars). The circles represent the results from the literature Ref $[7,8,10]$. The data were collected on increasing pressure. 


\section{Conclusions}

The major technological importance of this work is the use of relatively benign solvent such as THF and a derivative of commercially available salt for synthesis of high $\mathrm{T}$ molecular superconductor $\mathrm{Cs}_{3} \mathrm{C}_{60}$. The proposed route can open up the 5 opportunities for renewed interest for alkali metal fullerides and particular $\mathrm{Cs}_{3} \mathrm{C}_{60}$. One important aspect of this work is that modifications similar to work carried out by Janiak et al. ${ }^{17}$ for synthesis of $\mathrm{K}_{3} \mathrm{C}_{60}$. (THF) $)_{14}$ - which involved slow recrystallization - may help to produce single crystals of $\mathrm{Cs}_{3} \mathrm{C}_{60}$. The access to single crystals would be important development in the field of organic superconductors and 10 will allow a much better understanding over complex structure - properties relationship of novel molecular high temperature superconductors.

\section{Acknowledgements}

K.P. and M.J.R. thank the financial support by EPSRC (EP/G037132 and EP/G037949) and by the European Union FP7-NMP-2011-EU-Japan project

${ }_{15}$ LEMSUPER under contract no. 283214. We also thank STFC for access to the synchrotron X-ray facilities at Diamond (where we thank C. Tang for his assistance on beamline I11). K.P. is a Royal Society Wolfson Research Merit Award holder and M.J.R. is a Royal Society Research Professor.

\section{Experimental}

\section{${ }_{20}$ Synthesis of the reducing agent $\operatorname{Cs}\left[\mathrm{Mn}\left(\mathrm{Cp}^{*}\right)_{2}\right]$}

Caesium metal (548.0 mg, 4.12mmol, Sigma-Aldrich, 99.5\%) and napthalene (530.0 $\mathrm{mg}, 4.14 \mathrm{mmol}$, Alfa Aesar, 99.6\%) were reacted together for 1 hour at $30{ }^{\circ} \mathrm{C}$ in THF (120 ml, Fisher, GLC grade, 99.8+\%) purified by distillation from sodium (Sigma Aldrich, 99.5\%)-benzophenone ketyl (Sigma-Aldrich, Reagentplus, 99\%). This 25 solution was then transferred by cannula to a vessel containing $\operatorname{Mn}\left(\mathrm{Cp}^{*}\right)_{2}$ (additionally purified by sublimation, $1.34 \mathrm{~g}, 4.12 \mathrm{mmol}$, Sigma Aldrich, 97\%) under constant stirring and left for 15 minutes to react. THF was then evaporated off into a liquid nitrogen trap and the resulting orange solid suspended with hexane (40 $\mathrm{ml}$ ). The suspension was then separated using a frit and the precipitate washed with 30 three lots of hexane $(20 \mathrm{ml})$ before being dried under dynamic vacuum until a pressure of at least $1 \times 10^{-1}$ mbar was achieved. The dried material was ground in a glove box giving a yield of $92.8 \%$. The composition of the reducing agent was ascertained by microanalysis $(\mathrm{CHN})$ by sealing tin cans with the sample inside in a He glove box. Theory (C: 52.42; H: 6.60; N: 0)/ Experiment (C: 52.21; H: 6.54; N: 350 ).

\section{Synthesis of $\mathrm{Cs}_{3} \mathrm{C}_{60}$ from $\mathrm{Cs}\left[\mathrm{Mn}\left(\mathrm{Cp}^{*}\right)_{2}\right]$ reducing agent and $\mathrm{C}_{60}$}

The optimised synthesis of $\mathrm{Cs}_{3} \mathrm{C}_{60}$ material was carried out by making two suspensions of $\mathrm{Cs}\left[\mathrm{Mn}\left(\mathrm{Cp}^{*}{ }_{2}\right)\right](137.5 \mathrm{mg}, 0.3 \mathrm{mmol})$ and $\mathrm{C}_{60}(72.0 \mathrm{mg}, 0.1 \mathrm{mmol})$ in $160 \mathrm{ml}$ and $20 \mathrm{ml}$ of THF respectively. The $\mathrm{Cs}\left[\mathrm{Mn}\left(\mathrm{Cp}^{*}{ }_{2}\right)\right]$ suspension was then 40 added drop wise to the $\mathrm{C}_{60}$ through a cannula over 90 minutes. The use of cannula allowed the slow addition of reducing agent to the $\mathrm{C}_{60}$ by a pressure differential. The reaction mixture quickly turned from orange to the dark red colour indicative of the $\mathrm{C}_{60}{ }^{-3}$ anion. The mixture was then stirred for 30 minutes and the volume

6 | [journal], [year], [vol], 00-00 
subsequently reduced to $20 \mathrm{ml}$. The $\mathrm{Cs}_{3} \mathrm{C}_{60}$.xTHF material was precipitated from the solution by the slow addition of dry hexane $(20 \mathrm{ml})$. Initially the black crystalline product became visible leaving a pale yellow solution remaining. The slow addition of the remaining hexane produced large particles of $\mathrm{Cs}_{3} \mathrm{C}_{60}$.xTHF leaving a clear 5 yellow solution. Once precipitated, the product was filtered through a frit, washed three times with hexane $(10 \mathrm{ml})$ and dried by passing argon over the material. The product consisting $109.2 \mathrm{mg}$ of the red brown material, quickly losing it appearance by turning into black solid, was ground up in the glove box. In order to improve crystallinity of the as made material and remove the solvent $100 \mathrm{mg}$ were annealed 10 under dynamic vacuum $\left(1 \times 10^{-5} \mathrm{mbar}\right)$ for 15 hours at $350^{\circ} \mathrm{C}$ (heating protocol: $\left.\mathrm{RT} \rightarrow 5^{\circ} / \mathrm{min}, 350^{\circ} \mathrm{C}, 15 \mathrm{hrs} \rightarrow 5^{\circ} / \mathrm{min} \mathrm{RT}\right)$. After the annealing protocol, $79.5 \mathrm{mg}$ of a black was recovered and stored in the glovebox.

\section{Scaled-up synthesis of $\mathrm{Cs}_{3} \mathrm{C}_{60}$ from $\mathrm{Cs}\left[\mathrm{Mn}\left(\mathrm{cp}^{*}\right)_{2}\right]$ reducing agent and $\mathrm{C}_{60}$}

${ }_{15}$ The reaction protocol was carried out as described above by scaling up the amount of reagents and solvents. The amount of the as made product was $171.5 \mathrm{mg}$. Annealing of $160 \mathrm{mg}$ of the as made sample yielded $153.1 \mathrm{mg}$ of black powder which was stored in the glove box.

\section{Synchrotron X-ray diffraction}

20 High-resolution synchrotron powder X-ray diffraction data were collected at ambient temperature using the high-resolution powder diffractometers on beamline I1 1 at Diamond, UK $(\lambda=0.82716 \AA)$.

TOPAS Academic V5 software was used for refinement of the collected PXRD patterns where the input files were written in JEdit. ${ }^{19}$

${ }_{25}$ The Rietveld refinement of $\mathrm{Cs}_{3} \mathrm{C}_{60}$ phase was carried out based on the structural model used by Ganin et al. in the space group $F m \overline{3} m .{ }^{8}$ In order to minimize the effect of parameters correlations on the accuracy of refinements they were carried out in consecutive steps as described by McCusker et.al. ${ }^{20}$ The background was fitted using a Chebychev polynomial function of no more than 13 terms for data 30 obtained using synchrotron radiation. The peak shapes of the PXRD patterns of the materials presented in this work were done using standard or combinations of standard analytical peak shapes. Diffraction patterns of fullerides, like $\mathrm{Cs}_{3} \mathrm{C}_{60}$ materials reported here, have complex anisotropic profile broadening are dealt with using a anisotropic peak shape which was developed on this type of material. ${ }^{11}$

35 A Pawley refinement was used for the impurity phase as the simplest method of determining a suitable peak shape function, so that the peak profile could be determined in the absence of information about atomic parameters. The crystal structure of $\mathrm{K}_{3} \mathrm{C}_{60} \cdot(\mathrm{THF})_{14}$ and space group $C 2 / m$ was used for the fit. The background, zero offset, axial divergence and cell parameters were refined along 40 with Thompson-Cox-Hastings (TCHZ) function. ${ }^{22}$

\section{Raman spectroscopy}

Raman spectra of samples $\mathbf{1}$ and $\mathbf{2}$ were collected at ambient temperature using a 514.5-nm laser with a JY LabRam-HR Spectrometer operated in back-scattered ${ }_{45}$ geometry over a sample area of $500 \mu \mathrm{m}^{2}$. The typical acquisition times were $20 \times 6 \mathrm{~s}$. Calibration was performed by referencing the spectrometer to the

[journal], [year], [vol], 00-00 | 7 
$520.07 \mathrm{~cm}^{-1}$ silicon line. $\mathrm{C}_{60}$ and $\mathrm{Cs}_{6} \mathrm{C}_{60}$ samples were used as standards $\left(\mathrm{A}_{\mathrm{g}}(2)\right.$ peaks at 1,468 and $1,430 \mathrm{~cm}^{-1}$, respectively). The resulting Raman mode shift per one electron transferred to $\mathrm{C}_{60}$ was found $\sim 6.33 \mathrm{~cm}^{-1}$.

\section{Magnetic measurements}

5 High-pressure magnetic measurements were undertaken using an easyLab Technologies piston-cylinder high pressure cell (Mcell10) with an upper limit of hydrostatic pressure of 10.6 kbar; high-purity Sn was used as an in situ manometer with Daphne oil as pressure transmitting medium, and magnetization data were collected on 20 -mg samples loaded in an argon-filled glovebox under ZFC and FC 10 protocols at $20 \mathrm{Oe}$.

\section{References}

${ }^{a}$ Department of Chemistry, University of Liverpool, Crown Street, Liverpool L69 7ZD, UK Fax: +44 (0) 151794 3588; Tel: +44 (0) 151794 3499;

15 E-mail: m.j.rosseinsky@liverpool.ac.uk

${ }^{b}$ Department of Chemistry, Durham University, South road, Durham DH1 3LE, UK

E-mail:k.prassides@durham.ac.uk

${ }^{c}$ School of Chemistry, University of Glasgow, Glasgow G12 8QQ, UK

${ }^{d}$ WPI Research Center, Advanced Institute for Materials Research, Tohoku University, Sendai 980 20 8577, Japan

$\dagger$ Electronic Supplementary Information (ESI) available: PXRD of Mn(cp*) ${ }_{2}$ and Cs[Mn(cp* $\left.)_{2}\right]$ products; Tables with atomic parameters; Raman spectroscopy; High P SQUID measurements. See DOI: $10.1039 / \mathrm{b} 000000 \mathrm{x} /$

25 1. O. Zhou, R. M. Fleming, D. W. Murphy, M. J. Rosseinsky, A. P. Ramirez, R. B. Vandover and R. C. Haddon, Nature, 1993, 362, 433.

2. S. Margadonna, E. Aslanis and K. Prassides, J. Am. Chem. Soc., 2002, 124, 10146.

3. Y. Iwasa, H. Shimoda, Y. Miyamoto, T. Mitani, Y. Maniwa, O. Zhou and T. T. M. Palstra, J. Phys. Chem. Solids, 1997, 58, 1697.

30 4. H. Shimoda, Y. Iwasa, Y. Miyamoto, Y. Maniwa and T. Mitani, Phys. Rev. B, 1996, 54, 15653.

5. K. Prassides, Cur. Opin. Solid State Mater. Sci., 1997, 2, 433.

6. M. J. Rosseinsky, Chem. Mat., 1998, 10, 2665.

7. A. Y. Ganin, Y. Takabayashi, P. Jeglic, D. Arcon, A. Potocnik, P. J. Baker, Y. Ohishi, M. T. McDonald, M. D. Tzirakis, A. McLennan, G. R. Darling, M. Takata, M. J. Rosseinsky and K. 35 Prassides, Nature, 2010, 466, 221.

8. A. Y. Ganin, Y. Takabayashi, Y. Z. Khimyak, S. Margadonna, A. Tamai, M. J. Rosseinsky and K. Prassides, Nat. Mater., 2008, 7, 367.

9. Y. Takabayashi, A. Y. Ganin, P. Jeglic, D. Arcon, T. Takano, Y. Iwasa, Y. Ohishi, M. Takata, N. Takeshita, K. Prassides and M. J. Rosseinsky, Science, 2009, 323, 1585.

40 10. M. T. McDonald, PhD thesis, 2010.

11. T. T. M. Palstra, O. Zhou, Y. Iwasa, P. E. Sulewski, R. M. Fleming and B. R. Zegarski, Solid State Commun., 1995, 93, 327.

12. L. Echegoyen and L. E. Echegoyen, Acc. Chem. Res., 1998, 31, 593.

13. D. Dubois, G. Moninot, W. Kutner, M. T. Jones and K. M. Kadish, J. Phys. Chem., 1992, 96, 7137.

14. D. L. Reger, S. R. Goode and D. W. Ball, Chemistry: Principles and Practice, Brooks/Cole, 2009.

15. X. H. Liu, W. C. Wan, S. M. Owens and W. E. Broderick, J. Am. Chem. Soc., 1994, 116, 5489.

16. J. L. Robbins, N. M. Edelstein, S. R. Cooper and J. C. Smart, J. Am. Chem. Soc., 1979, 101, 3853.

17. C. Janiak, S. Muhle, H. Hemling and K. Kohler, Polyhedron, 1996, 15, 1559.

18. M. G. Mitch and J. S. Lannin, Phys. Rev. B, 1995, 51, 6784.

8 | [journal], [year], [vol], 00-00

This journal is (C) The Royal Society of Chemistry [year] 
19. Bruker AXS, Karlsruhe, 2003.

20. L. B. McCusker, R. B. Von Dreele, D. E. Cox, D. Louer and P. Scardi, Journal of Applied Crystallography, 1999, 32, 36-50.

21. P. W. Stephens, Journal of Applied Crystallography, 1999, 32, 281-289.

5 22. R. A. Young, The Rietveld method, Oxford University Press, Oxford, 1993.

[journal], [year], [vol], 00-00 | 9

This journal is @ The Royal Society of Chemistry [year] 